\title{
Ultrafine Iridium Oxide Nanorods Synthesized by Molten Salt Method toward Electrocatalytic Oxygen and Hydrogen Evolution Reactions
}

\author{
Jahangeer Ahmed and Yuanbing Mao* \\ Department of Chemistry, University of Texas Rio Grande Valley, Edinburg, Texas 78539, USA \\ *Author to whom correspondence should be addressed. E-mail: yuanbing.mao@utrgv.edu. Tel.: \\ $+1-956-665-2417$.
}

\begin{abstract}
Ultrafine iridium oxide nanorods ( $\left.\mathrm{IrO}_{2} \mathrm{NRs}\right)$ were successfully synthesized using a molten salt method at $650^{\circ} \mathrm{C}$. The structural and morphological characterizations of these $\mathrm{IrO}_{2} \mathrm{NRs}$ were carried out by powder X-ray diffraction, Raman spectroscopy and electron microscopic techniques. Compared to commercial $\mathrm{IrO}_{2}$ nanoparticles ( $\mathrm{IrO}_{2} \mathrm{NPs}$ ) and previous reports, these $\mathrm{IrO}_{2} \mathrm{NRs}$ show enhanced electrocatalytic activity to oxygen and hydrogen evolution reactions by passing either $\mathrm{N}_{2}$ or $\mathrm{O}_{2}$ gas in a $0.5 \mathrm{M} \mathrm{KOH}$ electrolyte before electrochemical measurements, including cyclic voltammetry, chronoamperometry and electrochemical impedance spectroscopy. Specifically, the current densities from the as-synthesized $\mathrm{IrO}_{2} \mathrm{NRs}$ and commercial $\mathrm{IrO}_{2} \mathrm{NPs}$ were measured in $0.5 \mathrm{M} \mathrm{KOH}$ electrolyte to be 70 and 58 (OER, deaerated, at $0.6 \mathrm{~V}$ versus $\mathrm{Ag} / \mathrm{AgCl}$ ), 71 and 61 (OER, $\mathrm{O}_{2}$, from -0.10 to $1.0 \mathrm{~V}$ versus $\mathrm{Ag} / \mathrm{AgCl}$ at $50 \mathrm{mV} / \mathrm{s}$ ), and 25 and 14 (HER, deaerated, at $-1.4 \mathrm{~V}$ versus $\mathrm{Ag} / \mathrm{AgCl}$ ) $\mathrm{mA} / \mathrm{cm}^{2}$, respectively. These results are comparable with, and in most cases, higher than reported data in the literature. Therefore, the current study reports not only a novel synthetic process for $\mathrm{IrO}_{2}$ but also a high efficient $\mathrm{IrO}_{2}$ nanostructure, and it is expected that these $\mathrm{IrO}_{2} \mathrm{NRs}$ can serve as a benchmark in the development of active OER and HER (photo)electrocatalysts for various applications.
\end{abstract}


KEYWORDS: $\mathrm{IrO}_{2}$; nanorods; molten salt synthesis; oxygen evolution reaction (OER); hydrogen evolution reaction (HER) 


\section{Introduction}

The storage of renewable energy using hydrogen "fuel" has been viewed as a viable mechanism by electrolysis of water into oxygen and hydrogen fuels, but is hampered by the slow kinetics of the oxygen evolution reaction (OER). Hence there is a broad effort to improve performance of currently used materials and develop new materials. Iridium oxide $\left(\mathrm{IrO}_{2}\right)$ is an effective stable electro-catalyst which can lower the over-potential and keep a remarkable current to improve the efficiency of fuel generation technologies. ${ }^{1,2}$ Nanostructured $\mathrm{IrO}_{2}$ materials have been highlighted as the most promising electrode materials to enhance the electrocatalytic activity in both OER and hydrogen evolution reaction (HER) from the photo-electrochemical watersplitting and electrolysis., ${ }^{3,4,5,6,7,8}$ Nanocrystalline $\mathrm{IrO}_{2}$ and $\mathrm{RuO}_{2}$ are recognized to be the best electrocatalysts for HER and OER in both acidic and alkaline media even though a growing body of OER and HER catalysts containing abundant, inexpensive transition metals and their oxides have recently appeared in the literature. ${ }^{9,10}$ The continuous use of relatively expensive materials by industry is because the economics of electrolytic hydrogen production are governed mainly by catalytic performance rather than the catalyst cost and earth-abundant materials are typical not as stable. ${ }^{11}$ Recently, Stoerzinger et al have reported the surface orientated oxygen evolution activities of $\mathrm{IrO}_{2}$ and $\mathrm{RuO}_{2}$ in $\mathrm{O}_{2}$-saturated $0.1 \mathrm{M} \mathrm{KOH}$ electrolyte at $1.53 \mathrm{~V}$ versus reversible hydrogen electrode. ${ }^{12}$ The potentials range of $\mathrm{IrO}_{2}$ electrocatalysts for OER were reported from $0.77 \mathrm{~V}$ to $1.5 \mathrm{~V}$ using acidic and alkaline solutions as the electrolytes. ${ }^{7,10,13,14,15,16,17,18,19}$ The lowest potential of $\mathrm{IrO}_{2}$ nanostructures was reported of $0.77 \mathrm{~V}$ for the OER in $0.1 \mathrm{M}$ phosphate buffer solution using ITO electrode. ${ }^{13}$

$\mathrm{IrO}_{2}$ nanostructures have also been used widely as the electrocatalysts for the OER in proton exchange membrane (PEM) water electrolysis, ${ }^{15,16,20}$ solid polymer electrolyte (SPE) 
electrolyzer, ${ }^{13,17}$ photocatalytic and electrolysis of water oxidation, etc. ${ }^{3,6,8,13} \mathrm{IrO}_{2}$ nanostructures were also used as the electrocatalysts in the oxygen reduction, ${ }^{1}$ oxidation of carbon mono-oxide, methanol and ethanol, etc. ${ }^{21,22}$ Apart from the electrocatalysis, $\mathrm{IrO}_{2}$ nanostructures were also used in several other applications including sensing, ${ }^{23}$ field emission, ${ }^{24,25} \mathrm{Li}$-air battery, ${ }^{26}$ electrical properties, etc. ${ }^{27}$

$\mathrm{IrO}_{2}$ nanostructured materials were mostly synthesized by metal organic chemical vapor deposition (MOCVD) method. ${ }^{23,28,29,30,31,32,33,34,25} \mathrm{~A}$ variety of $\mathrm{IrO}_{2}$ nanostructures have also been produced by various other techniques, including vapor phase transport process, ${ }^{35}$ electrochemical synthesis, ${ }^{13}$ arc vaporization, ${ }^{36}$ hydrothermal, ${ }^{4}$ reactive radio frequency magnetron sputtering (RFMS) ${ }^{37}$ sol-gel ${ }^{38,39}$ wetness method, ${ }^{9}$ Adams fusion method, ${ }^{15,16}$ sulfite complex route, ${ }^{14}$ thermal decomposition of precursor $\left(\mathrm{H}_{2} \mathrm{IrCl}_{6}\right){ }^{17}$ oleylamine-mediated synthesis, etc. ${ }^{10}$ With a closer look, it can be found that many of these methods employ expensive, complex, unstable and not-environmentally-friendly iridium-containing precursors followed with tedious synthetic procedure in complicated experimental setups. Molten salt synthesis process is the cost effective, stable and eco-friendly method compared to above reported methods. This method has also been employed earlier as a simple and facile approach in the synthesis of various nanostructured materials. ${ }^{40,41,42}$ Herein, we report the successful synthesis of $\mathrm{IrO}_{2}$ nanorods with an average diameter of $\sim 15 \mathrm{~nm}$ and length of $\sim 200 \mathrm{~nm}$ for the first time using iridium tetrachloride as precursor in a molten salt of sodium chloride and potassium chloride mixture at $650^{\circ} \mathrm{C}$ for $12 \mathrm{~h}$ in ambient air atmosphere. The structural and morphological characterizations of $\mathrm{IrO}_{2} \mathrm{NRs}$ were investigated by powder X-ray diffraction (PXRD), Raman spectroscopy, energy dispersive X-ray studies, single point BET surface area measurements and electron microscopic studies. Note that an effective electrocatalyst can lower the over-potential to sustain the current and, therefore, to 
improve the efficiency of an electrocatalyst toward the gas evolution reactions due to loss of minimum energy in the electrochemical reactions. Electrocatalytic studies of the $\mathrm{IrO}_{2} \mathrm{NRs}$ toward OER and HER have been investigated by cyclic voltammetry (CV) and chronoamperometry (CA) in alkaline $0.5 \mathrm{M} \mathrm{KOH}$ aqueous electrolyte versus $\mathrm{Ag} / \mathrm{AgCl}$ electrode, and obtained results were compared to commercial $\mathrm{IrO}_{2} \mathrm{NPs}$ and previously reported work.

\section{Experimental}

\section{Materials and method}

The following reagents were used in the synthesis of the $\mathrm{IrO}_{2} \mathrm{NRs}$ by the molten salt process: $\mathrm{IrCl}_{4}$ (Alfa Aesar, 99.95\%), $\mathrm{NaCl}$ (Alfa Aesar, 99.0\%), and $\mathrm{KCl}$ (Sigma Aldrich, 99.0\%). The precursors were taken with the molar ratio of 1:30:30 of $\mathrm{IrCl}_{4}: \mathrm{NaCl}: \mathrm{KCl}$ and ground together in an agate mortar pestle for 20 minutes. The resulting mixture was transferred to a covered rectangular crucible and kept at $650^{\circ} \mathrm{C}$ for $12 \mathrm{~h}$ in a programmable high temperature furnace with the heating and cooling rate of $5^{\circ} \mathrm{C} /$ minute in air. The resulting products were washed with deionized water several times and then dried at $60^{\circ} \mathrm{C}$ for $6 \mathrm{~h}$ in oven. Commercial $\mathrm{IrO}_{2}$ nanoparticles (NPs) from Sigma Aldrich (99.9\%) were used to compare the electrocatalytic activity with the as-synthesized $\mathrm{IrO}_{2} \mathrm{NRs}$.

\section{Characterizations}

The resulting fine black colored powder of the $\mathrm{IrO}_{2}$ NRs was characterized initially by PXRD on a Rigaku MiniFlex X-ray diffractometer using Ni-filtered $\mathrm{Cu}-\mathrm{K} \alpha$ radiation. Diffraction patterns were recorded with a step size and scan speed of $0.01^{\circ}$ and $1 \mathrm{~s}$, respectively, on an aluminum sample holder. Raman scattering data was recorded by employing the back-scattering geometries on a Bruker SENTERRA RAMAN microscope with an objective of 20X optical microscope. 
The excitation line $(785 \mathrm{~nm})$ of an $\mathrm{Ar}+$ laser beam was focused to a spot size of $5 \mu \mathrm{m}$ with a laser power of $25 \mathrm{~mW}$. The used spectral resolution range was $3-5 \mathrm{~cm}^{-1}$ with the integration time of 100 s. Field emission SEM study was carried out with a ZEISS SIGMA VP electron microscope operated at $5 \mathrm{kV}$. Transmission electron microscopy (TEM), high resolution TEM (HRTEM), and selected area electron diffraction (SAED) analyses were carried out with a Hitachi $\mathrm{H}-9500$ electron microscope operated at $300 \mathrm{kV}$. The samples for TEM studies were prepared by dispersing the $\mathrm{IrO}_{2} \mathrm{NRs}$ in ethanol via utrasonic process for 5 minutes, and a drop of the formed suspension was put onto a carbon coated copper grid, and then dried in air. Surface area analysis was performed on a Micromeritics ASAP 2020 Surface Area and Porosity Analyzer with nitrogen at cryogenic temperature (77.3 K).

\section{Preparation of electrode materials and electrochemical measurements}

The working electrode was modified with the as-synthesized $\mathrm{IrO}_{2} \mathrm{NRs}$ for the electrochemical studies toward OER and HER. The $\mathrm{IrO}_{2}$ nanostructures modified electrodes were prepared by mixing the nanopowder, carbon black and PVDF. The powder of $\mathrm{IrO}_{2} \mathrm{NRs}$ was ground with carbon black and PVDF in the weight fraction of 75:15:10, with a small amount of ethanol and then pasted on the glassy carbon electrode. The prepared electrode materials were then dried overnight at $65^{\circ} \mathrm{C}$ in vacuum oven. The electrochemical studies were carried out with a potentiostat/galvanostat electrochemical work station (Metrohm Autolab B.V.) at room temperature. The electrochemical work station contains three electrodes including the $\mathrm{IrO}_{2} \mathrm{NRs}$ coated glassy carbon as the working electrode, $\mathrm{Ag} / \mathrm{AgCl}$ as the reference electrode and a $\mathrm{Pt}$ wire as the counter electrode. CV measurements were carried out at different scan rates of 100, 50, 20 and $10 \mathrm{mV} / \mathrm{s}$ with a peak window between 0 and $-1.4 \mathrm{~V}$ versus the $\mathrm{Ag} / \mathrm{AgCl}$ electrode for the HER and from 0 to $1.0 \mathrm{~V}$ versus the $\mathrm{Ag} / \mathrm{AgCl}$ electrode for the OER. CA characterization was 
carried out for $200 \mathrm{~s}$ at various fixed potentials versus the $\mathrm{Ag} / \mathrm{AgCl}$ electrode for HER (at -1.4, 1.2, -1.0 and $-0.9 \mathrm{~V}$ ) and OER (at $0.60,0.65,0.70$ and $0.75 \mathrm{~V}$ ). CV and CA measurements were carried out in an alkaline electrolyte of $0.5 \mathrm{M} \mathrm{KOH}$ aqueous solution. Prior to the electrochemical measurements, nitrogen gas was flown through the electrolyte solution for 5 minutes to remove dissolved air from the electrolyte. Also, electrochemical measurements were run in $0.5 \mathrm{M} \mathrm{KOH}$ solution saturated with $\mathrm{O}_{2}$ toward the OER. Note that freshly prepared electrodes and electrolytes were used in each measurement and the current density of the $\mathrm{IrO}_{2}$ electrocatalysts was calculated using the geometric electro-active surface area of electrode from

Randles-Sevcik equation. ${ }^{43,44,45}$ Also note that the geometric electro-active surface area of freshly prepared electrodes could vary due to the variation of amount of pasted materials on fresh glassy carbon electrode. Electrochemical impedance spectroscopic (EIS) studies were also carried in three electrode configuration using the same Metrohm Autolab electrochemical work station with the frequency ranging from $100 \mathrm{mHz}$ to $100 \mathrm{kHz}$ at $1.0 \mathrm{~V}$ in $0.5 \mathrm{M} \mathrm{KOH}$ solution.

\section{Results and discussion}

The phase purity of our as-synthesized $\mathrm{IrO}_{2}$ NRs was characterized by PXRD and Raman spectroscopy. The observed reflections from the synthesized $\mathrm{IrO}_{2}$ NRs (Figure 1a) could be perfectly indexed with the peaks of (110), (101), (200), (111), (210) and (211) on the basis of rutile phase $\mathrm{IrO}_{2}$ with tetragonal crystal structure (JCPDS file \# 88-0288). The relative strong intensity of the (101) peak is an evidence of the orientation of the <101> plane of rutile phase of the $\mathrm{IrO}_{2}$ NRs. As detected by PXRD, the commercial $\mathrm{IrO}_{2}$ NPs (Sigma Aldrich, $99.9 \%$ ) were amorphous in nature. In addition to XRD data, evidence regarding the chemical composition of the $\mathrm{IrO}_{2}$ nanomaterials was obtained from Raman spectroscopy. Three characteristic Raman 
bands (Figure 1b) are identified at 548, 720 and $740 \mathrm{~cm}^{-1}$ from the $\mathrm{IrO}_{2}$ NRs and commercial $\mathrm{IrO}_{2}$ NPs. Well correlated with those of $\mathrm{IrO}_{2}$ nanocrystals, these bands can be correspondingly assigned to the first order $E_{\mathrm{g}}, B_{2 \mathrm{~g}}$, and $A_{1 \mathrm{~g}}$ phonon bands of rutile $\mathrm{IrO}_{2}$ structure, respectively. ${ }^{37}$ Field emission SEM (FESEM) images (Figure 2a-c) of the as-synthesized $\mathrm{IrO}_{2}$ product confirm the formation of ultrafine nanorods, appearing in rectangular shape with the diameter ranging from $8 \mathrm{~nm}$ to $20 \mathrm{~nm}$ and an average diameter of $15 \mathrm{~nm}$. Energy dispersive studies (Inset of Figure 2a) confirmed that our as-synthesized $\mathrm{IrO}_{2}$ NRs only contain iridium and oxygen elements with no other impurities, which clearly support the PXRD and Raman data from the $\mathrm{IrO}_{2} \mathrm{NRs}$ (Figure 1). FESEM image of the commercial $\mathrm{IrO}_{2} \mathrm{NPs}$ shows the spherical shape with an average size of $\sim 60 \mathrm{~nm}$ (Figure $2 \mathrm{~d}$ ).

TEM and HRTEM studies (Figure 3) were employed to characterize the morphology, size and crystalline behavior of the resulting $\mathrm{IrO}_{2}$ NRs. TEM image (Figure 3a) confirms the formation of $\mathrm{IrO}_{2} \mathrm{NRs}$ with the average diameter and length of $\sim 15 \mathrm{~nm}$ and $\sim 200 \mathrm{~nm}$, respectively. HRTEM image shows a lattice spacing value of $3.20 \AA$, which is consistent with (110) plane of $\mathrm{IrO}_{2} \mathrm{NRs}$ (Figure 3b). Electron diffraction (ED) pattern of the $\mathrm{IrO}_{2} \mathrm{NRs}$ shows the circular fashion of the spots due to (110), (101), (200), (210), (211), and (220) planes which indicate the formation of tetragonal crystal structure of $\mathrm{IrO}_{2}$ NRs (Figure 3c). Both the HRTEM image and ED pattern confirm the crystalline behavior of the $\mathrm{IrO}_{2} \mathrm{NRs}$.

Molten salt synthetic process (i.e. using chlorides as the salts) is a significant approach to synthesize a wide variety of materials with high crystallinity, including the formation of nanospheres, nanocubes, and nanorods. The surface and interface energies between the transition metal precursors and the molten salts minimize the activation energies to form unusual morphologies of products. ${ }^{46}$ The morphology of the nanomaterials in molten salts could be 
influenced by various parameters including precursors, synthetic conditions, nature of the salts, diffusion of the salts, and the solubility of the constituents. ${ }^{46-47}$ Recently Rørviket al had reported that the sodium chloride plays a crucial role in the growth of nanorods of ternary oxides in the molten salt synthesis while no rod shaped morphology was observed without sodium chloride. ${ }^{47}$ We observed similar phenomena here from the synthesis of the $\mathrm{IrO}_{2} \mathrm{NRs}$ with the chloride mixture as the molten salt. The molten salt method had also been used earlier in the synthesis of nanorods of other binary, ${ }^{48,49}$ and ternary oxides, ${ }^{47,50,51}$ but it is the first time for $\mathrm{IrO}_{2}$ as reported in this manuscript.

Electrochemical stability and gas evolution activity of the iridium oxides electrocatalysts depend on the chemical and structural nature as well as the size and morphology of the materials and their synthetic conditions. ${ }^{19,52}$ Crystalline metal oxides are electrochemically more stable compared to amorphous oxides materials for the gas evolution reactions. ${ }^{19}$ However if amorphous $\mathrm{IrO}_{2}$ nanoparticles were calcined at high temperature $\left(>550^{\circ} \mathrm{C}\right)$ then it could cause the agglomeration of the nanoparticles which may lead to increase their particle size. Therefore, calcined commercial $\mathrm{IrO}_{2}$ nanoparticles would not show enhancement of their electrochemical activity towards the OER and HER due to larger particle size. The electrochemical CV and CA measurements were carried out to evaluate the electrocatalytic activity of the $\mathrm{IrO}_{2} \mathrm{NRs}$ and commercial $\mathrm{IrO}_{2}$ NPs toward OER and HER. Figure 4a shows the cyclic voltammograms of the $\mathrm{IrO}_{2} \mathrm{NRs}$ with a peak window from 0 to $1.0 \mathrm{~V}$ versus $\mathrm{Ag} / \mathrm{AgCl}$ with scan rates of $100,50,20$ and $10 \mathrm{mV} / \mathrm{s}$ to study their redox behaviors. The peak observed at $\sim 0.55 \mathrm{~V}$ could be due to the transformation of $\mathrm{Ir}^{3+}$ to $\mathrm{Ir}^{4+} .{ }^{10-11}$ Noticeably, the electrocatalytic oxidation current was observed beyond this potential in the cyclic voltametric curves due to the following reaction occurs at the electrode surface: $4 \mathrm{OH}^{-} \rightarrow 2 \mathrm{H}_{2} \mathrm{O}+2 \mathrm{O}_{2}+4 \mathrm{e}^{-}$. $\mathrm{IrO}_{2} \mathrm{NPs}$ supported on glassy carbon electrode 
were also employed for the OER in acidic $\left(0.1 \mathrm{M} \mathrm{HClO}_{4}\right)$ and alkaline $(0.1 \mathrm{M} \mathrm{KOH})$ solutions at $1.5 \mathrm{~V}$ versus reversible hydrogen electrode (RHE) by using a rotating ring disc electrode. ${ }^{10}$ So far, the lowest potential of $\mathrm{IrO}_{2}$ nanostructures for the OER was reported of $0.77 \mathrm{~V}$ using the ITO electrode from 0 to $1.4 \mathrm{~V}$ versus $\mathrm{Ag} / \mathrm{AgCl}$ at a scan rate of $20 \mathrm{mVs}^{-1}$ in $0.1 \mathrm{M}$ phosphate buffer solution. ${ }^{13}$ Herein, this is noteworthy that the OER starts at a much lower potential using our $\mathrm{IrO}_{2}$ NRs compared to previous reports. ${ }^{10,13}$

Chronoamperometry is a potentiostatic experiment and true quantitative measurements to study the electro-catalytic activity of the materials with three electrode systems at the fixed potential with time. It is important to use less energy for current generation and to find optimal oxygen generating electrocatalysts to minimize the energy loss. Previously, current densities of $\mathrm{IrO}_{2}$ nanostructures were reported of $10 \mathrm{~mA} / \mathrm{cm}^{2}$ at $1.7 \mathrm{~V}$ vs $\mathrm{Hg} / \mathrm{Hg}_{2} \mathrm{SO}_{4} / \mathrm{K}_{2} \mathrm{SO}_{4}$ in $0.1 \mathrm{M} \mathrm{KOH}$ and

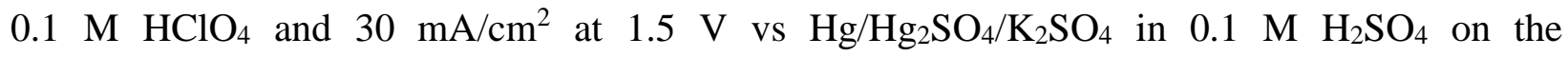
literature. ${ }^{10,53} \mathrm{IrO}_{2}$ nanostructures as the electrocatalysts generate a very high current (100 $\mathrm{mA} / \mathrm{cm}^{2}-1.7 \mathrm{~A} / \mathrm{cm}^{2}$ ) using PEM and SPE water electrolysis at $1.8 \mathrm{~V} \cdot{ }^{14,16,17}$ Herein, Figure $4 \mathrm{~b}$ shows chronoamperometric measurements of the $\mathrm{IrO}_{2} \mathrm{NRs}$ supported on glassy carbon electrode at the fixed potentials varied from $0.6 \mathrm{~V}$ to 0.75 . In our experiment, when the potential is switched off then the electrochemical reaction stops and hence current drops drastically. We also observed that the erosion of the materials (from the working electrode) occurred at the higher voltage during OER. Using Randles-Sevcik equation and the geometric electro-active surface area $\left(0.70 \mathrm{~cm}^{2}\right)$ of the $\mathrm{IrO}_{2} \mathrm{NR}$ coated electrode, the current densities were found to be $86,82,78$ and $70 \mathrm{~mA} / \mathrm{cm}^{2}$ at the potentials of $0.60,0.65,0.70$ and $0.75 \mathrm{~V}$, respectively. ${ }^{43,44,45}$ Therefore, even our synthesis method to make these $\mathrm{IrO}_{2} \mathrm{NRs}$ is very facile and cost-efficient using simple precursor, the obtained OER current densities could be comparable with and even higher than 
what previously have been reported in the literature. Figure $4 \mathrm{c}$ shows the cyclic voltammograms of the commercial $\mathrm{IrO}_{2} \mathrm{NPs}$ with a peak window from -1.4 to $1.2 \mathrm{~V}$ versus $\mathrm{Ag} / \mathrm{AgCl}$ with scan rates of 200,50 , and $25 \mathrm{mV} / \mathrm{s}$. In $\mathrm{CV}$, an anodic sweep corresponds to the scan towards the positive potential while cathodic sweep denotes the scan towards the negative potential. By comparing the voltammograms from the as-synthesized $\mathrm{IrO}_{2} \mathrm{NRs}$ with those from commercial $\mathrm{IrO}_{2} \mathrm{NPs}$ for OER, we clearly observe that the $\mathrm{IrO}_{2} \mathrm{NRs}$ show superior electrocatalytic activity over the commercial $\mathrm{IrO}_{2} \mathrm{NPs}$ toward the OER in $0.5 \mathrm{M} \mathrm{KOH}$ solution at $0.6 \mathrm{~V}$ versus $\mathrm{Ag} / \mathrm{AgCl}$ electrode (Fig. 4a and 4c).

Figure $4 \mathrm{~d}$ shows the chronoamperometric voltammogram of the three electrodes coated by the $\mathrm{IrO}_{2} \mathrm{NRs}$, commercial $\mathrm{IrO}_{2} \mathrm{NPs}$ and no materials. The as-synthesized $\mathrm{IrO}_{2} \mathrm{NRs}_{\text {generate higher }}$ current density $\left(70 \mathrm{~mA} / \mathrm{cm}^{2}\right.$, calculated by using the geometric electroactive surface area of electrode of $\left.0.70 \mathrm{~cm}^{2}\right)$ than the commercial $\mathrm{IrO}_{2} \mathrm{NPs}\left(58 \mathrm{~mA} / \mathrm{cm}^{2}\right.$, calculated by using the geometric electroactive surface area of electrode of $0.12 \mathrm{~cm}^{2}$ ) at $0.6 \mathrm{~V}$ versus $\mathrm{Ag} / \mathrm{AgCl}$ electrode. The chronoamperometry to the current generation depends on many aspects of electrocatalyticactive materials. For example, the dependence of electro-catalytic activity on morphological and orientation of nanostructured materials has been reported. ${ }^{12,54}$ Similarly, for $\mathrm{IrO}_{2}$ nanostructures, the generated current density depends on both the surface area and morphology as a conjunction of both faradaic and non-faradaic processes. In the faradaic process, charges being transferred across the electrode-electrolyte interface are governed by the Faraday's law, and electrons transferred from the $\mathrm{IrO}_{2}$ atoms to water molecules to generate hydroxide ions and hydrogen molecules as OER and HER, respectively. For the non-faradaic process, only the formation of the electrical double layer is motivated. From electron microscopic measurements (Figures $2 \& 3$ ), the diameter and length of the as-synthesized $\mathrm{IrO}_{2} \mathrm{NRs}$ were found to be $\sim 15 \mathrm{~nm}$ and $\sim 200 \mathrm{~nm}$, 
respectively, and the diameter of the commercial $\mathrm{IrO}_{2} \mathrm{NPs}$ was $\sim 60 \mathrm{~nm}$. The surface area of the $\mathrm{IrO}_{2} \mathrm{NRs}$ and commercial $\mathrm{IrO}_{2} \mathrm{NPs}$ was measured by single point BET and found to be $\sim 14 \mathrm{~m}^{2} / \mathrm{g}$ and $\sim 12 \mathrm{~m}^{2} / \mathrm{g}$, respectively. As expected, the surface area increases with decreasing grain size of the $\mathrm{IrO}_{2}$ nanostructures. However, other than difference on surface area, different crystallinity (rutile crystal phase $v s$ amorphous phase, Figure 1) and morphology (nanorod $v s$ nanoparticle) may also play important roles on the variation of OER current density between the $\mathrm{IrO}_{2} \mathrm{NRs}_{\text {and }}$ commercial $\mathrm{IrO}_{2}$ NPs. Further investigation is needed on these aspects in the future.

Figure 4e shows EIS spectra of the $\mathrm{IrO}_{2} \mathrm{NRs}$ and commercial $\mathrm{IrO}_{2} \mathrm{NPs}$ in $0.5 \mathrm{M} \mathrm{KOH}$ solution. The collected Nyquist plots of the $Z^{\prime}$ real vs negative $Z^{\prime \prime}$ imaginary at $1.0 \mathrm{~V}$ vs $\mathrm{Ag} / \mathrm{AgCl}$ show the observed impedance semicircles from both electrode materials. The ohmic resistance of charge transfer $\left(R_{\mathrm{ct}}\right)$ of the $\mathrm{IrO}_{2} \mathrm{NRs}$ was found to be $\sim 0.35 \mathrm{ohm} \cdot \mathrm{cm}^{2}$, lower than that of the commercial $\mathrm{IrO}_{2} \mathrm{NPs}\left(R_{c t}=\sim 0.52 \mathrm{ohm} \cdot \mathrm{cm}^{2}\right)$ and similar with that of the reported $\mathrm{Pt} / \mathrm{IrO}_{2}$ electrocatalyst. ${ }^{2}$ Both the Faradic reactions and electrical double-layer on the electrode surface are represented by $R_{\mathrm{ct}}$. The impedance response, governed by the faradic gas evolutions, supports the enhanced electrocatalytic activity of $\mathrm{IrO}_{2} \mathrm{NRs}$ over the commercial $\mathrm{IrO}_{2} \mathrm{NPs}$.

The oxygen evolution activity of $\mathrm{IrO}_{2}$ electrocatalysts has also been carried out in $0.5 \mathrm{M} \mathrm{KOH}$ aqueous solution saturated with $\mathrm{O}_{2}$ gas. Similarly freshly prepared electrodes and electrolyte solutions were used in three electrode system, but $\mathrm{O}_{2}$ gas flowed for $30 \mathrm{~min}$ before starting $\mathrm{CV}$ experiments. The cyclic voltammograms of the $\mathrm{IrO}_{2}$ nanostructures were collected by applying potential ranging from -0.10 to $1.0 \mathrm{~V}$ versus $\mathrm{Ag} / \mathrm{AgCl}$ electrode at the scan rate of $50 \mathrm{mV} / \mathrm{s}$ (Figure 4f). From the CV curves, it can be easily observed that the $\mathrm{IrO}_{2} \mathrm{NRs}$ generate higher current compared to the $\mathrm{IrO}_{2}$ NPs. The current density of freshly prepared electrodes containing $\mathrm{IrO}_{2} \mathrm{NRs}$ (geometric electroactive surface area of electrode $=0.10 \mathrm{~cm}^{2}$ ) and $\mathrm{IrO}_{2} \mathrm{NPs}($ geometric 
electroactive surface area of electrode $=0.30 \mathrm{~cm}^{2}$ ) were found to be $71 \mathrm{~mA} / \mathrm{cm}^{2}$ and $61 \mathrm{~mA} / \mathrm{cm}^{2}$, respectively. These results are consistent with those measured in deaerated electrolyte, and that the electrocatalytic activity of the as-synthesized $\mathrm{IrO}_{2} \mathrm{NRs}$ is higher than the commercial and many previously reported $\mathrm{IrO}_{2}$ electrocatalysts.

Previously, $\mathrm{IrO}_{2}$ nanostructured materials have been used as an electrocatalyst with SPE in HER. ${ }^{9}$ Meanwhile, hydrogen has been proposed as a potential replacement for our rapidly depleting fossil fuel resources. ${ }^{55}$ Boodts and Trasatti were reported two decades ago that $\mathrm{IrO}_{2}$ is a good electrocatalyst for HER and shown the current density in the order of $10^{-3} \mathrm{~A} / \mathrm{cm}^{2} .^{56}$ Cheng et al had reported that carbon supported $\mathrm{IrO}_{2}$ and $\mathrm{RuO}_{2}$ generated current density in the range from $10^{-6}$ to $10^{-3} \mathrm{~A} / \mathrm{cm}^{2}$ with the scan window from -0.3 to $0.3 \mathrm{~V}$ using $0.5 \mathrm{M} \mathrm{H}_{2} \mathrm{SO}_{4}$ as an electrolyte. ${ }^{9}$ Therefore, HER performance of the $\mathrm{IrO}_{2}$ NRs was also evaluated by applying a negative potential versus $\mathrm{Ag} / \mathrm{AgCl}$ electrode. Figure 5a shows the $\mathrm{CV}$ curves of freshly prepared $\mathrm{IrO}_{2} \mathrm{NR}$ electrodes in deaerated $0.5 \mathrm{M} \mathrm{KOH}$ solution by nitrogen gas for 5 min by scanning with different rates of $100,50,20$ and $10 \mathrm{mV} / \mathrm{s}$ from 0 to $-1.4 \mathrm{~V}$ versus $\mathrm{Ag} / \mathrm{AgCl}$ electrode. It was observed that HERs started from $-0.80 \mathrm{~V}$ on the surface of working electrode containing the $\mathrm{IrO}_{2}$ NRs versus $\mathrm{Ag} / \mathrm{AgCl}$ according to the following reaction: $2 \mathrm{H}_{2} \mathrm{O}+2 \mathrm{e}^{-} \rightarrow \mathrm{H}_{2}+2 \mathrm{OH}^{-}$. Chronoamperometric studies of $\mathrm{IrO}_{2} \mathrm{NRs}$ were also carried out for HER over the surface of $\mathrm{IrO}_{2}$ electrode in $0.5 \mathrm{M} \mathrm{KOH}$ at fixed potentials with time (Figure 5b). The current densities from the chronoamperometric measurements using the electroactive surface area of electrode $\left(0.35 \mathrm{~cm}^{2}\right)$ for HER were found to be $8,12,14$ and $25 \mathrm{~mA} / \mathrm{cm}^{2}$ at the potentials of $-0.90,-1.00,-1.20$ and $1.40 \mathrm{~V}$, respectively. The generated cathodic current is directly proportional to the rate of hydrogen evolution, so the higher currents generated at $-1.4 \mathrm{~V}$ may be due to higher electron transfer rate from electrolyte to the electrode surface compared to those at $-0.90,-1.00,-1.20 \mathrm{~V}$. 
These results are comparable with and even higher than literature results, even direct comparison should be done with caution due to different measurement conditions. ${ }^{9,56}$ Figure $5 \mathrm{c}$ shows the comparative chronoamperometric studies of the $\mathrm{IrO}_{2} \mathrm{NRs}$ and commercial $\mathrm{IrO}_{2} \mathrm{NPs}$ at $-1.4 \mathrm{~V}$ versus $\mathrm{Ag} / \mathrm{AgCl}$ electrode in $0.5 \mathrm{M} \mathrm{KOH}$ electrolyte. For $\mathrm{HER}$, the current density of the $\mathrm{IrO}_{2}$ NRs $\left(25 \mathrm{~mA} / \mathrm{cm}^{2}\right)$ was found to be nearly double to that of the commercial $\mathrm{IrO}_{2}$ NPs (14 $\mathrm{mA} / \mathrm{cm}^{2}$ ). Therefore, the $\mathrm{IrO}_{2}$ NRs show enhanced electrocatalytic HER activity and enhanced OER activity, as discussed above, compared to the commercial $\mathrm{IrO}_{2} \mathrm{NPs}$ and other reported work.

\section{Conclusions}

In this paper, we report the successful synthesis of ultrafine $\mathrm{IrO}_{2}$ nanorods with average diameter and length of $15 \mathrm{~nm}$ and $200 \mathrm{~nm}$, respectively, using a facile molten salt method at $650^{\circ} \mathrm{C}$ in air. These $\mathrm{IrO}_{2}$ NRs possess enhanced electrocatalytic OER and HER activities compared to the commercial $\mathrm{IrO}_{2}$ nanoparticles after passing either $\mathrm{N}_{2}$ or $\mathrm{O}_{2}$ gas into the electrolyte before experiments, as confirmed by cyclic voltammetry and chronoamperometric measurements and supported by electrochemical impedance spectroscopic studies. Specifically, the as-synthesized $\mathrm{IrO}_{2} \mathrm{NRs}$ generate higher OER current density $\left(70 \mathrm{~mA} / \mathrm{cm}^{2}\right)$ than the commercial $\mathrm{IrO}_{2} \mathrm{NPs}(58$ $\mathrm{mA} / \mathrm{cm}^{2}$ ) at $0.6 \mathrm{~V}$ versus $\mathrm{Ag} / \mathrm{AgCl}$ electrode in deaerated $0.5 \mathrm{M} \mathrm{KOH}$ electrolyte. In $0.5 \mathrm{M} \mathrm{KOH}$ electrolyte saturated with $\mathrm{O}_{2}$, the OER current density of the $\mathrm{IrO}_{2} \mathrm{NRs}$ and $\mathrm{IrO}_{2} \mathrm{NPs}$ were found to be $71 \mathrm{~mA} / \mathrm{cm}^{2}$ and $61 \mathrm{~mA} / \mathrm{cm}^{2}$, respectively. Moreover, in $0.5 \mathrm{M} \mathrm{KOH}$ deaerated electrolyte, the HER current density of the $\mathrm{IrO}_{2} \mathrm{NRs}\left(25 \mathrm{~mA} / \mathrm{cm}^{2}\right)$ was found to be nearly double to that of the commercial $\mathrm{IrO}_{2} \mathrm{NPs}\left(14 \mathrm{~mA} / \mathrm{cm}^{2}\right)$. These current densities are comparable with, and in most 
cases, higher than reported results in the literature, while the synthesis method employed here for these $\mathrm{IrO}_{2} \mathrm{NRs}$ is much more facile, cost-efficient and environmentally-friendly.

\section{ACKNOWLEDGMENT}

The authors thank the support from the Welch Foundation \#BG-0017, the Air Force Office of

Scientific Research (award \# FA9550-12-1-0159), and the National Science Foundation under

DMR grant \# 0934157 (PREM-UTPA/UMN-Science and Engineering of Polymeric and

Nanoparticle-based Materials for Electronic and Structural Applications). The authors also thank

to Mr. Q. Li for taking SEM images and Ms. J. Cruz for performing BET measurements.

\section{REFERENCES}

1. Chang, C. H.; Yuen, T. S.; Nagao, Y.; Yugami, H., Electrocatalytic activity of iridium oxide nanoparticles coated on carbon for oxygen reduction as cathode catalyst in polymer electrolyte fuel cell. Journal of Power Sources 2010, 195 (18), 5938-5941.

2. Yao, W.; Yang, J.; Wang, J.; Nuli, Y., Chemical deposition of platinum nanoparticles on iridium oxide for oxygen electrode of unitized regenerative fuel cell. Electrochemistry Communications 2007, 9 (5), 1029-1034.

3. Frame, F. A.; Townsend, T. K.; Chamousis, R. L.; Sabio, E. M.; Dittrich, T.; Browning, N. D.; Osterloh, F. E., Photocatalytic water oxidation with nonsensitized $\mathrm{IrO}_{2}$ nanocrystals under visible and UV light. Journal of the American Chemical Society 2011, 133 (19), 72647267.

4. Tang, J.; Kong, B.; Wang, Y.; Xu, M.; Wang, Y.; Wu, H.; Zheng, G., Photoelectrochemical detection of glutathione by $\mathrm{IrO}_{2}-\mathrm{Hemin}-\mathrm{TiO}_{2}$ nanowire arrays. Nano Letters 2013, 13 (11), 5350-5354.

5. Tilley, S. D.; Cornuz, M.; Sivula, K.; Grätzel, M., Light-induced water splitting with hematite: improved nanostructure and iridium oxide catalysis. Angewandte Chemie International Edition 2010, 49 (36), 6405-6408.

6. Youngblood, W. J.; Lee, S.-H. A.; Kobayashi, Y.; Hernandez-Pagan, E. A.; Hoertz, P. G.; Moore, T. A.; Moore, A. L.; Gust, D.; Mallouk, T. E., Photoassisted overall water splitting in a visible light-absorbing dye-sensitized photoelectrochemical cell. Journal of the American Chemical Society 2009, 131 (3), 926-927. 
7. Zhao, C.; E, Y.; Fan, L., Enhanced electrochemical evolution of oxygen by using nanoflowers made from a gold and iridium oxide composite. Microchimica Acta 2012, 178 (1-2), 107-114.

8. Hoertz, P. G.; Kim, Y.-I.; Youngblood, W. J.; Mallouk, T. E., Bidentate dicarboxylate capping groups and photosensitizers control the size of $\mathrm{IrO}_{2}$ nanoparticle catalysts for water oxidation. The Journal of Physical Chemistry B 2007, 111 (24), 6845-6856.

9. Cheng, J.; Zhang, H.; Ma, H.; Zhong, H.; Zou, Y., Study of carbon-supported $\mathrm{IrO}_{2}$ and $\mathrm{RuO}_{2}$ for use in the hydrogen evolution reaction in a solid polymer electrolyte electrolyzer. Electrochimica Acta 2010, 55 (5), 1855-1861.

10. Lee, Y.; Suntivich, J.; May, K. J.; Perry, E. E.; Shao-Horn, Y., Synthesis and activities of rutile $\mathrm{IrO}_{2}$ and $\mathrm{RuO}_{2}$ nanoparticles for oxygen evolution in acid and alkaline solutions. The Journal of Physical Chemistry Letters 2012, 3 (3), 399-404.

11. R.D.L. Smith, B. S., R.D. Fagan, S. Trudel, C.P. Berlinguette, Facile photochemical preparation of amorphous iridium oxide films for water oxidation catalysis. Chemistry of Materials 2014, 26, 1654-1659.

12. Stoerzinger, K. A.; Qiao, L.; Biegalski, M. D.; Shao-Horn, Y., Orientation-dependent oxygen evolution activities of rutile $\mathrm{IrO}_{2}$ and $\mathrm{RuO}_{2}$. The Journal of Physical Chemistry Letters 2014, 5 (10), 1636-1641.

13. Zhao, C.; Yu, H.; Li, Y.; Li, X.; Ding, L.; Fan, L., Electrochemical controlled synthesis and characterization of well-aligned $\mathrm{IrO}_{2}$ nanotube arrays with enhanced electrocatalytic activity toward oxygen evolution reaction. Journal of Electroanalytical Chemistry 2013, 688, 269274.

14. Siracusano, S.; Baglio, V.; Stassi, A.; Ornelas, R.; Antonucci, V.; Aricò, A. S., Investigation of $\mathrm{IrO}_{2}$ electrocatalysts prepared by a sulfite-couplex route for the $\mathrm{O}_{2}$ evolution reaction in solid polymer electrolyte water electrolyzers. International Journal of Hydrogen Energy 2011, 36 (13), 7822-7831.

15. Mayousse, E.; Maillard, F.; Fouda-Onana, F.; Sicardy, O.; Guillet, N., Synthesis and characterization of electrocatalysts for the oxygen evolution in PEM water electrolysis. International Journal of Hydrogen Energy 2011, 36 (17), 10474-10481.

16. Puthiyapura, V. K.; Pasupathi, S.; Su, H.; Liu, X.; Pollet, B.; Scott, K., Investigation of supported $\mathrm{IrO}_{2}$ as electrocatalyst for the oxygen evolution reaction in proton exchange membrane water electrolyser. International Journal of Hydrogen Energy 2014, 39 (5), 19051913.

17. Cruz, J. C.; Baglio, V.; Siracusano, S.; Ornelas, R.; Ortiz-Frade, L.; Arriaga, L. G.; Antonucci, V.; Aricò, A. S., Nanosized $\mathrm{IrO}_{2}$ electrocatalysts for oxygen evolution reaction in an SPE electrolyzer. Journal of Nanoparticle Research 2011, 13 (4), 1639-1646.

18. Gambardella, A. A.; Feldberg, S. W.; Murray, R. W., Electron transfer dynamics of iridium oxide nanoparticles attached to electrodes by self-assembled monolayers. Journal of the American Chemical Society 2012, 134 (13), 5774-5777.

19. Cherevko, S.; Reier, T.; Zeradjanin, A. R.; Pawolek, Z.; Strasser, P.; Mayrhofer, K. J. J., Stability of nanostructured iridium oxide electrocatalysts during oxygen evolution reaction in acidic environment. Electrochemistry Communications 2014, 48, 81-85.

20. Kadakia, K.; Datta, M. K.; Velikokhatnyi, O. I.; Jampani, P. H.; Kumta, P. N., Fluorine doped $(\mathrm{Ir}, \mathrm{Sn}, \mathrm{Nb}) \mathrm{O}_{2}$ anode electro-catalyst for oxygen evolution via PEM based water electrolysis. International Journal of Hydrogen Energy 2014, 39 (2), 664-674. 
21. Liu, Z.-P.; Jenkins, S. J.; King, D. A., Role of nanostructured dual-oxide supports in enhanced catalytic activity: theory of $\mathrm{CO}$ oxidation over $\mathrm{Au} / \mathrm{IrO}_{2} / \mathrm{TiO}_{2}$. Physical Review Letters 2004, 93 (15), 156102.

22. Jian, X.-H.; Tsai, D.-S.; Chung, W.-H.; Huang, Y.-S.; Liu, F.-J., Pt-Ru and Pt-Mo electrodeposited onto $\mathrm{Ir}-\mathrm{IrO}_{2}$ nanorods and their catalytic activities in methanol and ethanol oxidation. Journal of Materials Chemistry 2009, 19 (11), 1601-1607.

23. Chao, T. W.; Liu, C. J.; Hsieh, A. H.; Chang, H. M.; Huang, Y. S.; Tsai, D. S., Quartz crystal microbalance sensor based on nanostructured $\mathrm{IrO}_{2}$. Sensors and Actuators B: Chemical 2007, $122(1), 95-100$.

24. Chen, Z. G.; Pei, F.; Pei, Y. T.; De Hosson, J. T. M., A versatile route for the synthesis of single crystalline oxide nanorods: growth behavior and field emission characteristics. Crystal Growth \& Design 2010, 10 (6), 2585-2590.

25. Chen, Y. M.; Chen, C. A.; Huang, Y. S.; Lee, K. Y.; Tiong, K. K., Synthesis of $\mathrm{IrO}_{2}$ nanocrystals on carbon nanotube bundle arrays and their field emission characteristics. Journal of Alloys and Compounds 2009, 487 (1-2), 659-664.

26. Huang, K.; Li, Y.; Xing, Y., Increasing round trip efficiency of hybrid Li-air battery with bifunctional catalysts. Electrochimica Acta 2013, 103 (0), 44-49.

27. Mahmoud, S. A.; Al-Shomar, S. M.; Akl, A. A., Electrical characteristics and nanocrystalline formation of sprayed iridium oxide thin films. Advances in Condensed Matter Physics 2010, 2010.

28. Chen, C. A.; Chen, Y. M.; Huang, Y. S.; Tsai, D. S.; Liao, P. C.; Tiong, K. K., Synthesis and structural characterization of twinned $\mathrm{V}$-shaped $\mathrm{IrO}_{2}$ nanowedges on $\mathrm{TiO}_{2}$ nanorods via MOCVD. Journal of Alloys and Compounds 2009, 480 (1), 107-110.

29. Chen, C. A.; Chen, Y. M.; Huang, Y. S.; Tsai, D. S.; Tiong, K. K.; Du, C. H., Growth and characterization of $\mathrm{V}$-shaped $\mathrm{IrO}_{2}$ nanowedges via metal-organic vapor deposition. Nanotechnology 2008, 19 (46), 465607.

30. Chen, R. S.; Chen, Y. S.; Huang, Y. S.; Chen, Y. L.; Chi, Y.; Liu, C. S.; Tiong, K. K.; Carty, A. J., Growth of $\mathrm{IrO}_{2}$ films and nanorods by means of CVD: an example of compositional and morphological control of nanostructures. Chemical Vapor Deposition 2003, 9 (6), 301 305.

31. Chen, R. S.; Huang, Y. S.; Liang, Y. M.; Tsai, D. S.; Tiong, K. K., Growth and characterization of iridium dioxide nanorods. Journal of Alloys and Compounds 2004, 383 (1-2), 273-276.

32. Chen, R.-S.; Huang, Y.-S.; Liang, Y.-M.; Tsai, D.-S.; Chi, Y.; Kai, J.-J., Growth control and characterization of vertically aligned $\mathrm{IrO}_{2}$ nanorods. Journal of Materials Chemistry 2003, 13 (10), 2525-2529.

33. Wang, G.; Tsai, D.-S.; Huang, Y.-S.; Korotcov, A.; Yeh, W.-C.; Susanti, D., Selective growth of $\mathrm{IrO}_{2}$ nanorods using metalorganic chemical vapor deposition. Journal of Materials Chemistry 2006, 16 (8), 780-786.

34. Reui-San, C.; Hung-Min, C.; Ying-Sheng, H.; Dah-Shyang, T.; Kuan-Cheng, C., Morphological evolution of the self-assembled $\mathrm{IrO}_{2}$ one-dimensional nanocrystals. Nanotechnology 2005, 16 (1), 93.

35. Lee, Y.; Kang, M.; Shim, J. H.; Lee, N.-S.; Baik, J. M.; Lee, Y.; Lee, C.; Kim, M. H., Growth of highly single crystalline $\mathrm{IrO}_{2}$ nanowires and their electrochemical applications. The Journal of Physical Chemistry C 2012, 116 (34), 18550-18556. 
36. Satishkumar, B. C.; Govindaraj, A.; Nath, M.; Rao, C. N. R., Synthesis of metal oxide nanorods using carbon nanotubes as templates. Journal of Materials Chemistry 2000, 10 (9), 2115-2119.

37. Korotcov, A.; Hsu, H.-P.; Huang, Y.-S.; Tsai, D.-S., Raman scattering characterization of well-aligned $\mathrm{IrO}_{2}$ nanocrystals grown on sapphire substrates via reactive sputtering. Journal of Raman Spectroscopy 2006, 37 (12), 1411-1415.

38. Ardizzone, S.; Bianchi, C.; Borgese, L.; Cappelletti, G.; Locatelli, C.; Minguzzi, A.; Rondinini, S.; Vertova, A.; Ricci, P.; Cannas, C.; Musinu, A., Physico-chemical characterization of $\mathrm{IrO}_{2}-\mathrm{SnO}_{2}$ sol-gel nanopowders for electrochemical applications. Journal of Applied Electrochemistry 2009, 39 (11), 2093-2105.

39. Wang, G.; Cheng, F.; Yu, Y.; Liang, C.; Xu, T.; Pan, M., SC-IrO 2 NR-carbon hybrid: a catalyst with high electrochemical stability for oxygen reduction. Science China Chemistry 2013, 56 (1), 131-136.

40. Mao, Y., Facile molten-salt synthesis of double perovskite $\mathrm{La}_{2} \mathrm{BMnO}_{6}$ nanoparticles. $R S C$ Advances 2012, 2 (33), 12675-12678.

41. Mao, Y.; Guo, X.; Huang, J. Y.; Wang, K. L.; Chang, J. P., Luminescent nanocrystals with $\mathrm{A}_{2} \mathrm{~B}_{2} \mathrm{O}_{7}$ composition synthesized by a kinetically modified molten salt method. The Journal of Physical Chemistry C 2009, 113 (4), 1204-1208.

42. Zhou, H.; Mao, Y.; Wong, S. S., Probing structure-parameter correlations in the molten salt synthesis of $\mathrm{BaZrO}_{3}$ perovskite submicrometer-sized particles. Chemistry of Materials 2007, 19 (22), 5238-5249.

43. Taurino, I.; Carrara, S.; Giorcelli, M.; Tagliaferro, A.; De Micheli, G., Comparison of two different carbon nanotube-based surfaces with respect to potassium ferricyanide electrochemistry. Surface Science 2012, 606 (3-4), 156-160.

44. Min-Jung, S.; Dong-Hwa, Y.; Joon-Hyung, J.; Nam-Ki, M.; Suk-In, H., Comparison of effective working electrode areas on planar and porous silicon substrates for cholesterol biosensor. Japanese Journal of Applied Physics 2006, 45 (9R), 7197.

45. Aljabali, A. A. A.; Barclay, J. E.; Butt, J. N.; Lomonossoff, G. P.; Evans, D. J., Redox-active ferrocene-modified Cowpea mosaic virus nanoparticles. Dalton Transactions 2010, 39 (32), 7569-7574.

46. Yoon, K.; Cho, Y.; Kang, D., Molten salt synthesis of lead-based relaxors. Journal of Materials Science 1998, 33 (12), 2977-2984.

47. Rørvik, P. M.; Lyngdal, T.; Sæterli, R.; van Helvoort, A. T. J.; Holmestad, R.; Grande, T.; Einarsrud, M.-A., Influence of volatile chlorides on the molten salt synthesis of ternary oxide nanorods and nanoparticles. Inorganic Chemistry 2008, 47 (8), 3173-3181.

48. Wang, W.; Xu, C.; Wang, X.; Liu, Y.; Zhan, Y.; Zheng, C.; Song, F.; Wang, G., Preparation of $\mathrm{SnO}_{2}$ nanorods by annealing $\mathrm{SnO}_{2}$ powder in $\mathrm{NaCl}$ flux. Journal of Materials Chemistry 2002, 12 (6), 1922-1925.

49. Wang, W. Z.; Xu, C. K.; Wang, G. H.; Liu, Y. K.; Zheng, C. L., Preparation of smooth single-crystal $\mathrm{Mn}_{3} \mathrm{O}_{4}$ nanowires. Advanced Materials 2002, 14 (11), 837-840.

50. Cai, Z.; Xing, X.; Yu, R.; Sun, X.; Liu, G., Morphology-controlled synthesis of lead titanate powders. Inorganic Chemistry 2007, 46 (18), 7423-7427.

51. Mao, Y.; Banerjee, S.; Wong, S. S., Large-Scale Synthesis of single-crystalline perovskite nanostructures. Journal of the American Chemical Society 2003, 125 (51), 15718-15719.

52. Gorodetskii, V. V.; Neburchilov, V. A., Tantalum oxide effect on the surface structure and morphology of the $\mathrm{IrO}_{2}$ and $\mathrm{IrO}_{2}+\mathrm{RuO}_{2}+\mathrm{TiO}_{2}$ coatings and on the corrosion and 
electrochemical properties of anodes prepared from these. Russian Journal of Electrochemistry 43 (2), 223-228.

53. Ouattara, L.; Fierro, S.; Frey, O.; Koudelka, M.; Comninellis, C., Electrochemical comparison of $\mathrm{IrO}_{2}$ prepared by anodic oxidation of pure iridium and $\mathrm{IrO}_{2}$ prepared by thermal decomposition of $\mathrm{H}_{2} \mathrm{IrCl}_{6}$ precursor solution. Journal of Applied Electrochemistry 2009, 39 (8), 1361-1367.

54. Ahmed, J.; Trinh, P.; Mugweru, A. M.; Ganguli, A. K., Self-assembly of copper nanoparticles (cubes, rods and spherical nanostructures): Significant role of morphology on hydrogen and oxygen evolution efficiencies. Solid State Sciences 2011, 13 (5), 855-861.

55. D. Owens, A. H., L. Sun, and Y. Mao, Synthesis of VTMS(X)-HMS-3 Mesoporous Ordered Silica for Hydrogen Storage. International Journal of Hydrogen Energy 2015, 40, in press.

56. Boodts, J. C. F.; Trasatti, S., Hydrogen evolution on iridium oxide cathodes. Journal of Applied Electrochemistry 1989, 19 (2), 255-262. 